\title{
Teamwork and Physician Burnout: The Moderating Role of Perceived Organisational Support
}

\author{
Samuel Atingabili1, Wenxin Wang, ${ }^{1}{ }^{*}$, Isaac Adjei Mensah ${ }^{3}$, \\ Evelyn Agba Tackie ${ }^{1}$, Isaac Ahakwa1, Prince Owusu Sarkodie ${ }^{1}$ \\ ${ }^{1}$ School of Management, Jiangsu University, Zhenjiang, China \\ ${ }^{2}$ Department of Public Administration, Law School/Institute of Local Government Development, Shantou University, Shantou, \\ China \\ ${ }^{3}$ Institute of Applied Systems Analysis (IASA), School of Mathematics, Jiangsu University, Zhenjiang, China \\ Email: sammibill73@gmail.com, *wxwang@stu.edu.cn, isaacadjeimensahphd@outlook.com, \\ tackieevelyna@gmail.com, isaacahakwa@gmail.com,princesarkodie773@yahoo.com
}

How to cite this paper: Atingabili, S., Wang, W.X., Mensah, I.A., Tackie, E.A., Ahakwa, I. and Sarkodie, P.O. (2021) Teamwork and Physician Burnout: The Moderating Role of Perceived Organisational Support. Health, 13, 416-438.

https://doi.org/10.4236/health.2021.134034

Received: March 20, 2021

Accepted: April 19, 2021

Published: April 22, 2021

Copyright $\odot 2021$ by author(s) and Scientific Research Publishing Inc. This work is licensed under the Creative Commons Attribution International License (CC BY 4.0).

http://creativecommons.org/licenses/by/4.0/

\begin{abstract}
Burnout is an important issue which has attracted the attention of physicians and health practitioners. Several studies have reported the negative effect of physician burnout and the adverse effect it has on the individual and health institutions. This study therefore examined the moderating effect of perceived organizational support on the relationship between teamwork and physician burnout in the Chinese context. Using a survey data consisting of a sample of physicians from hospitals within the Jiangsu Province of China, we estimated three models in a hierarchical framework and identified that in the presence of respondent's demographic characteristics as control variables, perceived organizational support, play a very vital role in improving teamwork while reducing burnout among physicians.
\end{abstract}

\section{Keywords}

Burnout, Perceived Organizational Support, Teamwork, Hierarchical Regression Analysis

\section{Introduction}

China is a fast-developing country with a rapidly ageing population, combined with an increasing influx of immigrants, which has created an increased demand for health services. It is well known that shortage of physicians leads to decreased healthcare service. Chinese physicians are at the forefront of quick re- 
forms in the health care system. These include higher patient turnover, adoption of advanced new technologies, the need for personalized care, and renewed efficiency focus. The work of a physician is known to be an occupation that needs physical and mental energy. Nonetheless, physicians are known to be more vulnerable to burnout: a risk factor in the decision of physicians to have intentions to leave the job [1] [2]. Burnout in physicians may not vary from those of other occupations. However, physicians' reactions may be unique in certain ways, partially because burnout in physicians can have severe implications for patients.

The lifeline of every health system is health professionals who play a pivotal role in healthcare delivery [3]. Therefore, it is imperative to consider the effect of healthcare delivery on health personnels, particularly when the effect is negative. A major contributing factor that may affect the physician workforce's adequacy is physician burnout [4] [5]. The working climate in which employees currently operate demands more from them than in any previous time. The demands arising from the fulfilment of various roles and primary health care have to be met by physicians in health facilities. Physicians' work is not done in isolation; physician work is done by a team of coordinated workers who belong to the same unit, department, or health facility [6]. Teamwork refers to a collaborative and interdependent framework of behavioural processes between the members of a team that turn team resources (for instance, team member composition, organizational funding) into results (example include team performance) [7] [8]. As teamwork in organizations becomes increasingly important, predicting who has effective teamwork skills is paramount in personnel selection. McEwan, Ruissen [7] posits that various strategies can be employed to assess the efficacy of teamwork approaches, including individual attitudes and team-based, cognitions, and affective states.

Physician burnout has severe adverse effects on health practitioners and health organizations both at the individual and organization levels. It is therefore indispensable to recognize the clinical manifestation of burnout so as to avoid its occurrence. Reviewed literature indicates that physician burnout is work-related hazard that necessitates systems or organizational solution to mitigate it. Panagioti, Panagopoulou [9] and Olson, Marchalik [10], in systematic reviews and meta-analyses, reported that organizational strategies are more effective than individual-based interventions at minimizing burnout. Despite the fact that there is strong evidence for a connection between job resources (teamwork) and physician burnout, there is also a scarcity of data on the consequences of interactions effects. One of the key reasons for examining the moderating effect of perceived organizational support on the relationship between teamwork and physician burnout in this study is the lack of sufficient empirical studies. As a result, this research is necessary to gain a comprehensive understanding of the connection between teamwork and physician burnout, as well as to affirm the need for dynamic organisational support to reduce burnout.

The impact of perceived social support on the relationship between teamwork 
and physician burnout is investigated in this study. The study's research question is: What impact does perceived organisational support have on the connection between teamwork and physician burnout? The remaining parts of the paper are arranged as follows: Section 2 explores the theoretical context of perceived organisational support, teamwork and burnout, and further discusses the relationship between the variables; Section 3 presents the data and methodology used in this study; and Section 4 summarises the findings. The fifth and final segment discusses and concludes the study.

\section{Theoretical Literature Review and Hypothesis Development}

\subsection{Perceived Organisational Support (POS)}

Perceived organizational support (POS) reflects employees' perception of "the extent to which the organization values their contributions and cares about their well-being" [11]. The theory of perceived organizational support notes that POS evolves due to the social exchange relationship [12] with the organization and instils a sense of duty that contributes to positive attitudes and success [13]. According to Rhoades and Eisenberger [14], organisational support theory argues that a member of an organization's sense of support will increase if they perceive the organisation has treated them equally, procedurally, and in terms of rewards and working conditions. Perceived support can regulate negative emotions and buffering stress and dissatisfaction, as employees in collective cultural settings are more likely to regard perceived support as a meaningful coping resource for the organization [15].

Perceived organizational support sets out an assumption for employees in the workplace that more effort will be rewarded to achieve the organizational objectives. A study conducted by Altinoz, Cop [16] reported that workers would have an emotional bond with an organization. Therefore, when employees' perceive social support and needs for compliments and recognition are met, they can put forth greater effort to achieve organisational objectives by displaying higher levels of engagement and performance.

\subsection{Relationship between Teamwork and Burnout}

The Job Demands-Resource (JD-R) model, according to [17] [18] are psychological effects that occur as an individual features interfere with work characteristics, referring to both job burnout and work engagement. The model further suggests that any working environment can be characterized in two dimensions: job demands and job resources [17]. Job demands are elements of work that necessitates a long-term commitment of physical, mental, or cognitive that is correlated with physiological and psychological costs. Although job demands are not inherently negative, they can turn into negative job stressors, especially when the job requires high commitment and effort in fulfilling them [19]. Stress and burnout can lead to lower performance and efficiency and increased absenteeism and turnover [20]. Job resources, on the other hand, are psychological, 
physical, social, and job features of one's work that are instrumental in attaining job objectives, reducing job demands and related costs, and enhancing learning. Job resources are functional to the achievement of work objectives; they also improve personal development and growth.

The JD-R model second premise is that work-related stress and motivation are two distinct psychological mechanisms. The first is a health impairment process that indicates that stressful occupations or jobs with chronic job demands cause workers' mental and physical resources to be depleted and can thus lead to energy loss and health problems [18]. The second of the dual-process by the JD-R model, of which one is motivational, assumes that job resources can motivate, contribute to increased level of dedication to work, low cynicism levels, and outstanding results. Job resources can also have an intrinsic motivational role by encouraging workers' development, learning, and advancement. Furthermore, job resources can play an extrinsic motivational role because they help in achieving work objectives [17] [18]. Supportive co-workers and the right feedback from an individual's superior, for example, improve the probability of completing one's job objectives successfully.

Furthermore, the JD-R model postulates that the relationships between job demands and job resources are mediated on one side by stress reactions (thus burnout) and on the other by motivational processes (i.e., job satisfaction) [20] [21] [22]. Stress responses and motivational mechanisms are also postulated as mediators between job demands/resources and turnover [20]. According to some studies, job resources (i.e., social support) [19] [23] have been shown to lead to work engagement. According to Bakker and Demerouti [17], social support is a situational variable that has the ability to serve as a buffer against work stress. Social support is a direct resource because it is efficient in the achievement of work objectives. Therefore, collaborative support from co-workers will help an individual finish the job on time and reduce the tension caused by work overload [17]. This study examined the relationship of social support (teamwork) on burnout.

To the best of our knowledge, limited research has made studies on the JD-R model, which analyzed individual and unit-level variables, although several attempts were made to incorporate multi-level constructs [6] [18] [24]. For instance, in a study by Busch, Deci, and Laackmann (2013) [25], team understaffing was a major stressor for teams. More psychosomatic complaints were correlated with lower productivity in teamwork design beyond job demands and job resources. In another study conducted by González-Morales, Peiró [26] in primary and secondary schools in Spain, the impact of individual burnout level was controlled for six months into the study. The study found out that job resources, a common sense of burnout at the team level, was a stronger predictor of individual burnout. Individual perceptions of demands or resources were also found to be less closely linked to the development of burnout symptoms than a shared perception of a burnout atmosphere among co-workers.

A cross-sectional multisource study conducted by Welp, Rothen [27] involv- 
ing nurses and physicians as research participants revealed improved teamwork and lower burnout were recorded by clinicians who worked mainly day shifts. The study's results further revealed that physicians and clinicians experienced better teamwork and higher personal accomplishment in leadership positions. The study results showed that some clinical groups were at higher risk of burnout, particularly at night shifts, demonstrating the importance of encouraging teamwork with these groups of individuals who work during the night shift. Further, a study conducted by Montgomery, Spânu [6], the JD-R model was tested using multilevel analysis to determine the key and moderating effects of teamwork effectiveness among 1156 nurses in 93 departments across seven European countries. The study found out that teamwork effectiveness was positively correlated with engagement. Although the study found no proof that effectiveness in team work reduces the perception of job demands, commitment, both vigor and dedication. Therefore, from the above literature discussed extensively the study hypothesizes that

$\mathrm{H1}$ : There is a significant relationship between teamwork and physician burnout.

\subsection{The Moderating Effect of POS on the Relationship Teamwork: Physician Burnout}

The relationship between job demands (burnout) and job resources (teamwork), as well as the latter's moderating effect by the job resource POS, is explored in this study. In terms of the JD-R model, we expect that teamwork which is an important job resource will correlate with lower job burnout level. According to Montgomery, Spânu [6] depersonalisation and emotional exhaustion should reduce when one feels that work is shared. The JD-R model emphasises the motivating aspect of employment, which is particularly important for health workers at the frontline level. Job resources (e.g. teamwork) are likely to facilitate achievement of goals, which in turn will lead to positive attitudes towards work (job satisfaction and organizational commitment) and decreased withdrawal behaviour (reduced absenteeism and turnover) [17] [20]. This study focuses on the buffering effect of perceived organizational support (POS). The study assumes that POS would buffer the relationship between teamwork and burnout in such a way physician burnout is expected to reduce. According to Demerouti and Bakker [18] job resources (POS) can buffer the effects of job demands on burnout. This can help physicians cope with higher job demands. Based on the aforementioned, the following hypothesis is developed

H2: The relationship between teamwork and burnout is moderated by perceived organisational support.

\section{Materials and Methods}

\subsection{Methodology}

This recent paper endeavours to estimate the structural affiliations between team work and burnout of physicians by considering the moderating role of 
perceived organizational support. Of interest to us, this current study is an applied research which specifically centers on surveys from sample of health facilities in the Jiangsu Province of China. Taking into consideration the population of physicians in the province as a whole, it will not be easy executing this survey without sampling. As reported by Punch [28], not everyone can be analysed everywhere, doing everything, thus sampling decisions are of much importance. Specifically,the random sampling based on the stratification approach is employed to select a sample of forty-five (45) hospitals from the north, south and central of Jiangsu province ${ }^{1}$. Considering an estimated response rate of $90 \%$, we set $z=1.645$, hence the sample size should be a minimum of 374 for each level (north, south and central of Jiangsu Province). Based on this, a total of 1122 physicians were selected as participants and were surveyed using well-structured questionnaires. Notably, the empirical data were obtained in 2019 within a six-month duration. As noted, the structured-questionnaires were disseminated to physicians who are members of the CMDA and known to have much concept and experience when it comes to how burnout, teamwork and perceived organizational support relate. Prior to the dissemination of the questionnaires, participants from the various sampled hospitals received emial invitations. The concepts of informed consent and confidentiality were applied to all respondents in the survey. Physicians belonging to the Chinese Medical Doctors Association (CMDA) from were invited to participate in this survey. Nonetheless, 938 valid and correctly filled questionnaires were recovered for an effective response of $83.6 \%$. This thus indicates that, majority of accurate responses were obtained since most of the respondents involved had much concept on the issue under discussion. Among these number of respondents 569 were males representing $60.7 \%$ whereas the remaining (369) also representing $39.3 \%$ were females. Specifically, the average age pertaining to respondents involved in the study was 34.7 with an estimated dispersion parameter of 9.6 whiles the minimum and maximum age were correspondingly 18 years and 60 years. In terms of educational background report from the demographics features of respondents portrayed that majority representing 53.8\% (505) physicians have attained their first degrees followed by 234 physicians (24.9\%) who have master's degree with 97 physicians (10.3\%) having their Ph.D. The remaining 10.8\% (112 participants) perhaps were doing internships or perhaps under training with their senior high/Technical secondary/Junior college certificates. Considering the marital status of respondents, more than half of the sample employed (603 physicians representing 64.3\%) reported they are married while 317 participants $(33.8 \%)$ indicated they have not yet married (unmarried) with the remaining 18 respondents (1.9\%) being divorcees. Table 1 therefore gives a summary of demographic characteristics regarding participants of the study.

${ }^{1}$ Fifteen hospitals each were randomly selected from each stratum (north, south and central) of Jiangsu Province respectively. 
Table 1. Respondents demographic characteristics.

\begin{tabular}{cccc}
\hline Item & Scale & Frequency & Percentage \\
\hline Gender & Male & 369 & 39.30 \\
& Female & 569 & 60.7 \\
Age & $18-30$ & 413 & 44.03 \\
& $31-45$ & 380 & 40.51 \\
Education & $46-60$ & 141 & 15.03 \\
& $60+$ & 4 & 0.43 \\
& Undergraduate & 505 & 53.80 \\
& Master & 234 & 24.90 \\
& Ph.D. & 97 & 10.30 \\
Marital status & Senior high/Technical secondary/Junior college & 112 & 10.80 \\
& Unmarried & 317 & 33.80 \\
& Married & 603 & 64.30 \\
& Divorced & 18 & 1.90 \\
\hline
\end{tabular}

Source: Authors construction.

\subsection{Measurement of Constructs}

Considering the context of construct measurements, the questionnaire used in this study was structured to estimate the structural relationship between three main constructs variables which includes burnout, teamwork and perceived organizational support. In this study, burnout construct is the main response variable whereas teamwork construct is the explanatory variable with perceived organizational support construct being the moderating variable. Bearing in mind the concept behind this survey, burnout among physicians was gauged using translated Maslach Burnout Inventory (MBI), developed by Maslach, Jackson [29]. According to Wang, Zhang [30], the MBI is the most widely used instrument in burnout studies. The MBI scale ${ }^{2}$ according to Maslach, Jackson [31] is divided into three dimensions including emotional exhaustion, personal accomplishment and depersonalization. Based on the dimensions of the aforementioned sub-scales of burnout, we designed a 5-point Likert-scale containing a sum of nineteen (19) measurement items for these three sub-dimensions. Further questions for gathering information on teamwork were on the other hand solicited from the Healthy and Resilient Organization scale (HERO) [32]. In all, nine (9) measurement items in three different components, which are teamwork vigor, teamwork dedication and teamwork absorption, are used in measuring teamwork with an adoption from Torrente, Salanova [33]. Participants involved in the survey were therefore probed to rate the items measuring teamwork (example; willingness to do extra work without pay) with each based on a scale of 5-point Likert scale (1-strongly disagree, 2-disagree, 3-neither agree nor dis${ }^{2}$ Chinese Version of the MBI scale. 
agree, 4-agree and 5-strongly agree). In the case of perceived organizational support, another nine (9) measurement items were employed example "The hospital provides me with job security" with adoption from Eisenberger, Huntington [11]. All measurement items concerning perceived organizational support were measured also using the 5-point Likert scale. Summarily, Table 2 presents the constructs with their corresponding observed variables. Notably, this recent study further controlled for four demographic variables including gender of respondents which was measured as a dummy variable (two categories; male and female), age (18 - 30 years, 31 - 45 years, 46 - 60 years and 60+ years), education (undergraduate, masters, and Ph.D.) and marital status (unmarried, married and divorced). A critical analysis conducted by Schaufeli and Enzmann [34] reported gender and burnout are possibly related, but the pattern of their relationships was inconclusive, with some research showing higher emotional fatigue in women and others reporting the opposite. This is the reason why gender is employed as a control variable. Maslach, Schaufeli [35] also revealed in a study conducted on gender and burnout that higher levels of emotional exhaustion were reported by women while level of cynicism was reported to be high in men. Since age is consistently linked to burnout [34], it was taken into account as a control variable. Employees with a higher level of education were found to have higher levels of burnout in previous studies [36]. Marital status is also included because of its potential correlation with burnout and distress [37].

\subsection{Data Analysis}

With reference to the statement made by $\mathrm{Hu}$, Danso [38] information gathered from questionnaire disseminated in the raw state is not pertinent until it is translated into a decision-making information. Thus, the data analysis of this current study included decreasing the data obtained to a reasonable size, constructing summaries and applying statistical presumptions. In a systematic manner, the following steps are considered to evaluate the structural affiliations amid study constructs relying on the data obtained. With the exception of the demographic variables, data on the main constructs of interest (which includes burnout, teamwork, and perceived organizational behaviour) were cleaned and coded using specified 5-point Likert-scale as already mentioned in the previous section. Notably, the response strength was assigned 1 for strongly disagree responses whereas degree strength of 5 was aligned to strongly agree response. Aside all these being done, we proceeded with data integrity checks using an ensemble of prescribed approaches. Thus, from the first phase the study employed single factor test of Herman to examine issues regarding common method variance using the Principal Axis Factoring (PAF). Subsequently, the factor analysis based on the Principal Component Analysis (PCA) via the Varimax rotation was executed to check as to whether the measurement items pertaining to the employed study constructs formed one scale. Notably, the criteria for conducting 
Table 2. Constructs and measurement items summary.

\begin{tabular}{|c|c|c|c|}
\hline Construct & Indicator & Measurement items & Scale \\
\hline \multirow[t]{19}{*}{ Burnout } & BO1 & The hospital work made me tired & Ordinal [1] [2] [3] [4] [5] \\
\hline & $\mathrm{BO} 2$ & I get sick and tired of questions from patients and families & Ordinal [1] [2] [3] [4] [5] \\
\hline & $\mathrm{BO} 3$ & I worry that work would affect my mood & Ordinal [1] [2] [3] [4] [5] \\
\hline & $\mathrm{BO} 4$ & I often feel exhausted & Ordinal [1] [2] [3] [4] [5] \\
\hline & BO5 & At the end of the day, I feel very tired & Ordinal [1] [2] [3] [4] [5] \\
\hline & BO6 & I can effectively solve patients' problems & Ordinal [1] [2] [3] [4] [5] \\
\hline & $\mathrm{BO} 7$ & My patients often complain about me & Ordinal [1] [2] [3] [4] [5] \\
\hline & $\mathrm{BO} 8$ & I can effectively influence others through work & Ordinal [1] [2] [3] [4] [5] \\
\hline & BO9 & I work with coping attitude & Ordinal [1] [2] [3] [4] [5] \\
\hline & BO10 & I have the ability to create a relaxed work environment. & Ordinal [1] [2] [3] [4] [5] \\
\hline & BO11 & I get really excited when I solve patients' problems & Ordinal [1] [2] [3] [4] [5] \\
\hline & BO12 & I often make small mistakes in my work & Ordinal [1] [2] [3] [4] [5] \\
\hline & $\mathrm{BO} 13$ & I would like to study or work by myself & Ordinal [1] [2] [3] [4] [5] \\
\hline & BO14 & I worry that patients are not happy with the way I handle problems. & Ordinal [1] [2] [3] [4] [5] \\
\hline & BO15 & I often blame my patients & Ordinal [1] [2] [3] [4] [5] \\
\hline & BO16 & I have done a lot of meaningful works & Ordinal [1] [2] [3] [4] [5] \\
\hline & BO17 & I am not interested in scientific research & Ordinal [1] [2] [3] [4] [5] \\
\hline & BO18 & I felt nervous and afraid after a medical mistake & Ordinal [1] [2] [3] [4] [5] \\
\hline & BO19 & I always treat patients with caution & Ordinal [1] [2] [3] [4] [5] \\
\hline \multirow[t]{9}{*}{ Teamwork } & TW1 & During the task, my team feels full of energy & Ordinal [1] [2] [3] [4] [5] \\
\hline & TW2 & Willingness to do extra work without pay & Ordinal [1] [2] [3] [4] [5] \\
\hline & TW3 & Encouraging members to promote active participation & Ordinal [1] [2] [3] [4] [5] \\
\hline & TW4 & My team is enthusiastic about the task & Ordinal [1] [2] [3] [4] [5] \\
\hline & TW5 & Information sharing and problem solving & Ordinal [1] [2] [3] [4] [5] \\
\hline & TW6 & Cooperating with superiors to complete work & Ordinal [1] [2] [3] [4] [5] \\
\hline & TW7 & When my team is working, we forget everything else around us & Ordinal [1] [2] [3] [4] [5] \\
\hline & TW8 & Job changes acceptance & Ordinal [1] [2] [3] [4] [5] \\
\hline & TW9 & Maintenance of a good cooperative relationship & Ordinal [1] [2] [3] [4] [5] \\
\hline \multirow{9}{*}{$\begin{array}{l}\text { Perceived } \\
\text { Organizational } \\
\text { Support }\end{array}$} & POS1 & The hospital provides me with stable job security & Ordinal [1] [2] [3] [4] [5] \\
\hline & POS2 & The hospital cares about my personal growth and personal life & Ordinal [1] [2] [3] [4] [5] \\
\hline & POS3 & The hospital will pay my salary and bonus according to my performance & Ordinal [1] [2] [3] [4] [5] \\
\hline & POS4 & The hospital provides me with a good working environment & Ordinal [1] [2] [3] [4] [5] \\
\hline & POS5 & The treatment the hospital gave me was fair and reasonable & Ordinal [1] [2] [3] [4] [5] \\
\hline & POS6 & The hospital was willing to take responsibility for my medical actions & Ordinal [1] [2] [3] [4] [5] \\
\hline & POS7 & Hospitals should ensure the safety of their doctors (medical personnel) & Ordinal [1] [2] [3] [4] [5] \\
\hline & POS8 & $\begin{array}{l}\text { Even at the expense of some benefits, the hospital has to stick to its } \\
\text { established philosophy }\end{array}$ & Ordinal [1] [2] [3] [4] [5] \\
\hline & POS9 & $\begin{array}{l}\text { The hospital encourages doctors (medical staff) to an active part in its } \\
\text { mission building }\end{array}$ & Ordinal [1] [2] [3] [4] [5] \\
\hline
\end{tabular}


the PCA solely relied on the Kaiser-Meyer-Oklin (KMO) and Bartlett's test of sphericity. Thus, according to Cramer [39] the KMO test value is expected to be greater than 0.7 whereas that of the Bartlett's test of sphericity is supposed to be statistically significant for the PCA analysis to be executed. After the integrity checks relying on the Hemans single factor test together with the PCA analysis, the study finally estimated the various study hypothesis using hierarchical linear regression (HLR) analysis, which centers on estimating the path coefficients of the study constructs. In this case, specified series of hierarchical linear regression models are specified to be able to establish the relationships hypothesized to exist among employed constructs. Notably, all the data analysis pertaining to afore-mentioned methods are made possible using SPSS v.22. Theoretically, the details of the statistical methods employed in the study are briefly described in the subsequent section as follows.

\section{Factor Analysis}

Obtaining robust regression coefficients is regarded as a frequent problem in the estimation of the relationship between series of models. Therefore, a reduction regarding the number of variables achieved by means of factor analysis would alleviate this issue. Limiting the range of parameters decreases the number of regression parameters and the group of correlated variables needed to resolve multicollinearity problems. The downside pertaining to this is the loss of some information, which leads to the model losing its predictability. Theoretically, factor analysis is a method to decrease the original $n$ variables observed to $k$ unnoticed variables where all $X_{i}^{\text {s }}$ s can be represented with new variables $k$. This can be mathematically expressed as;

$$
\begin{gathered}
X_{1}-\mu_{1}=\gamma_{11} F_{1}+\gamma_{12} F_{1}+\gamma_{13} F_{1}+\cdots+\gamma_{1 k} F_{k}+U_{1} \\
X_{2}-\mu_{2}=\gamma_{21} F_{1}+\gamma_{22} F_{1}+\gamma_{23} F_{1}+\cdots+\gamma_{2 k} F_{k}+U_{2} \\
\vdots \\
X_{n}-\mu_{n}=\gamma_{n 1} F_{1}+\gamma_{n 2} F_{1}+\gamma_{n 3} F_{1}+\cdots+\gamma_{n k} F_{k}+U_{n}
\end{gathered}
$$

where $F_{j}, j=1,2, \cdots, k$ are common factors representing new variables, and $U_{i}, i=1,2, \cdots, n$ are the unique factors that are undetected. Homogeneously, the series of models specified in Equation (1) is summarized as;

$$
(x-\mu)=A f+u
$$

where $A$ denotes matrix comprising of $a_{i j}$ elements known as factor weightings, $x$ also stands for $n \times 1$ vector containing $X_{i}, i=1,2, \cdots, n$ whereas $u$ is an average vector of $X_{i}$ s. Also $f$ is a $k \times 1$ vector consisting of $F_{j}$ s where $j=1,2, \cdots, k^{3}$, while $U_{i}$ is presumed with mean of 0 , but a variance of $\sigma_{i}^{2}$ as they are from $n \times 1$ vector $u$. Addtionaly, it is assumed that the unique and common factors are uncorrelated. Hence, by making the covariance matrix of $x$ with $\Sigma$, the previous equation becomes:

$$
\Sigma=\mathrm{E}\left[(x-\mu)(x-\mu)^{\prime}\right]=A A^{\prime}+\psi
$$

\footnotetext{
${ }^{3} f$ is assumed to have a mean of 0 and variance of 1 (follows a normal distribution).
} 
where $\psi$ is a variance vector of $u_{i}$. Since the right side of Equation (3) consists only of unobserved data, different factors can be obtained in this process Helmers and Rogers [40].

\subsection{Hierarchical Linear Regression}

As already elaborated this recent study centers on estimating the moderating effect of perceived organizational support on the relationship between teamwork and burnout among physicians by controlling for demographic characteristics of respondents in the Jiangsu Province of China using hierarchical linear regression model (HRLM). Notably, teamwork in this case is classified as the explanatory variable whereas perceived organizational support and burnout are specified as moderating and response variables correspondingly. With the aim to reduce the issues pertaining to omission of variable biasness (OVB) the demographic characteristics of respondents which includes gender, age, education, and marital status were employed as control variables. Emphatically, the hierarchical regression model approach is a way to show if variables of interest gives a statistical significance pertaining to the variabilities in the dependent variable after accounting other variables. In the HRLM framework, series of regression models (linear or non-linear) are developed by adding up independent variables to previous models in each step till number of models of researchers' interest are obtained. The main goal is therefore to determine whether the newly introduced or included variable(s) within a specific model show(s) a significant improvement in the proportion of explained variance in the response variable. Theoretically, a linear model with $p$ explanatory variables is expressed as;

$$
y_{i}=\varnothing_{o}+\varnothing_{1} x_{i 1}+\varnothing_{2} x_{i 2}+\cdots+\varnothing_{p} x_{i p}+\mu_{i}
$$

where $x_{i j}$ represents the $t$ th observation on the thexplanatory variables, $\varnothing_{0}$ is a constant term, $y_{i}$ is the $t$ th observation of the response variable and $\varnothing_{1}, \cdots, \varnothing_{p}$ denotes the estimated effect of the regressors on the dependent variable.

Since regression models in a hierarchy framework consist of series of regression models as already elaborated, this present study specifies three different regression models so as to estimate the path coefficients and as well test the study hypotheses. In order to therefore estimate the relationship between variables as the various study hypotheses portrays, the following models have been developed in hierarchical manner as follows;

$$
\begin{gathered}
\mathrm{BO}=\varnothing_{0}+\varnothing_{1} \mathrm{GEN}+\varnothing_{2} \mathrm{AGE}+\varnothing_{2} \mathrm{EDU}+\varnothing_{2} \mathrm{MAR}+\mu_{i} \\
\mathrm{BO}=\varnothing_{0}+\varnothing_{1} \mathrm{GEN}+\varnothing_{2} \mathrm{AGE}+\varnothing_{3} \mathrm{EDU}+\varnothing_{4} \mathrm{MAR}+\varnothing_{5} \mathrm{TW}+\varnothing_{6} \mathrm{POS}+\mu_{i} \\
\mathrm{BO}=\varnothing_{0}+\varnothing_{1} \mathrm{GEN}+\varnothing_{2} \mathrm{AGE}+\varnothing_{3} \mathrm{EDU}+\varnothing_{4} \mathrm{MAR}+\varnothing_{5} \mathrm{TW} \\
+\varnothing_{6} \mathrm{POS}+\varnothing_{7} \mathrm{TW} * \mathrm{POS}+\mu_{i}
\end{gathered}
$$

where $\mathrm{BO}$ represents burnout, GEN, AGE, EDU and MAR are control variable (demographic characteristics) representing gender, age, education level and marital status of respondents, TW and POS are variables of interest meaning 
teamwork and perceived organizational support, $\mathrm{TW}^{\star} \mathrm{POS}$ is the interaction between teamwork and perceived organizational support which shows the moderating effect. Notably, Model 5 in the first place establishes the effects pertaining to the demographic characteristics of respondents on burnout, Model 6 also estimates the effect of teamwork and perceived organizational support on burnout when the demographic characteristics are being controlled whereas in order to estimate the interactive effect (moderating effect) of POS on the relationship between TW and BO, model 7 is developed.

\section{Results and Discussions}

\subsection{Common Method Variance}

With regards to designing the study questionnaires, the dependent factor (construct) together with the independent and moderating constructs were separated and items measuring the various constructs were intermixed in an attempt to minimize single-source method bias according to Podsakoff [41]. The measurement items of all the construct variables were subjected to the principal component analysis via the oblique rotation which suggested that issues of common method bias were not of much concern in the analysis. The measures were further subjected to single factor test of Herman to using the Principal Axis Factoring (PAF). The Herman's single-factor test revealed that the total variance explained is $21.49 \%$, which is far less than $50 \%$ indicating no issues of common method variance. This therefore affirms the outcome from the PCA using the oblique rotation approach.

\subsection{Construct Validity and Reliability Test}

Reliability mainly echoes the stability and consistency of the results when the measurement items are repeatedly measured. To test the reliability coefficient, the Cronbach's alpha statistic is considered. According to Nunnally [42], the estimated value of the reliability test based on the Cronbach's alpha is expected to be greater than or equal to 0.7. Thus, from the Cronbach's alpha test outcome, it is evident that the estimated reliability coefficients with respect to the various study constructs ranges from 0.764 to 0.915 and thus far greater than 0.7 respectively. This therefore exhibits a good scale of reliability as in line with the study of O'Leary-Kelly and Vokurka [43]. Also, Cronbach's alpha values if item is deleted are also estimated to ensure that items that do not contribute to a specific construct are discovered. Based on this, we discovered that six (6) items among the sum of thirty-seven (37) measurement items were removed in order to improve the reliability. These items include BO2 (I get sick and tired of questions from patients and families), BO6 (I can effectively solve patients' problems), BO9 (I work with coping attitude), BO11 (I get really excited when I solve patients' problems), BO16 (I have done a lot of meaningful works) and B017 (I am not interested in scientific research) which are specifically part of the measurement items of burnout construct. These measurement items were removed since 
their Cronbach's alpha value when item is deleted was greater than the Cronbach's alpha value of the burnout construct itself thus were not included in the factor analysis. Aside that all other measurement items including that of teamwork and perceived organization support were maintained since their corresponding Cronbach's alpha value when item is deleted were below the threshold corresponding to the Cronbach's alpha value of the various constructs. Further the composite reliability (CR) test is also implemented to measure the overall scale reliability of the study constructs. Results thus unveils that the estimates pertaining to the CR for the corresponding constructs are far greater than 0.8 , which proves that the research instruments are reliable.

Further validity refers to the degree to which a measurement construct can accurately measure what needs to be measured. Thus, in this study, the validity of the various study constructs was examined through the KMO (Keiser Mayer Oklin) sample adequacy test, Bartlett's Sphericity test, factor loadings based on the PCA together with the average variance explained (AVE). Specifically, Özdamar, Roden [44] has reported that, the overall test value of the KMO should be at least 0.6 whereas that of the Bartlett's Sphericity test should be substantial and statistically significant. Both tests (KMO and Bartlett's Sphericity test) concerning burnout and teamwork together with the perceived organizational support constructs correspondingly unveils that the data pertaining to the mentioned constructs are suitable for reduction analysis in other words factor analysis. Specifically, the KMO estimated value for both teamwork and perceived organizational support are greater than 0.9 whereas that of burnout is higher than 0.8. Considering the Bartlett Sphericity test's estimated values for the all the study constructs, there is an indication of substantial correlation between observed variables as it gives a statistically significant test values respectively. According to Hair, Black [45], a specific construct's measurement item is deemed significant if its corresponding factor loading exceeds 0.7 thresholds. Outline of results concerning the factor loadings for all measurement times for the respective constructs (physician burnout, teamwork, and perceived organizational support) via the PCA analysis shows that, all thirteen (13) retained measurement items measuring burnout (after eliminating 6 items among the sum of 19 items based on the reliability test) had their loadings to be correspondingly above the expected threshold of 0.7. Also, concerning the nine (9) items measuring teamwork, none was dropped since all their respective factor weights were reported to be greater than the aforementioned threshold. Finally, all the nine (9) measurement items also for perceived organizational support construct similarly had their all their corresponding factor loadings also to be above the standard threshold of 0.7. Further, concerning the convergence and discriminant validity examinations using the average variance extracted (AVE), Bagozzi and Yi [46] reported that the estimated value of AVE should not be less than 0.5. Relying on this assertion, we have enough evidence to conclude that there are substantial levels of convergence and discriminant va- 
lidity since all the AVE test values with respect to the various constructs are far greater than the given threshold and thus range from 0.613 to 0.704 . Table 3 therefore gives the summary of the results pertaining to the various construct reliability and validity tests.

\subsection{Descriptive Statistic}

Summarily, Table 4 displays the descriptive statistics with respect to the mean, standard deviation, kurtosis and skewness pertaining to burnout (BO)and, teamwork (TW), perceived organizational support (POS) together with the demographic characteristics of respondents (gender, age, educational status and marital status). Centering on the main constructs used in the study, the main explanatory variable of interest (TW) is evidenced to have the highest mean value of 4.287 with a dispersion parameter of 0.675 followed by the moderating variable (POS) which is characterised by an estimated mean value of 4.148 and standard deviation test value of 0.740 whereas the response variable (BO) is reported to have the least average value of 2.910 with a dispersion estimate of 0.393. Taking into account the control variables (demographic characteristics), the mean age of respondents was estimated to be 34.670 with a dispersion value of 9.597 followed by education $(M=5.340, S D=0.823)$ with gender and marital status being the demographic variables with the least mean and dispersion values correspondingly. Specifically, in the case of skewness and kurtosis statistics, the general rule of thumb is that, for a series to follow a normal distribution the skewness together with the kurtosis test values are expected to be approximately 0 and 3 correspondingly. Hence, as Table 4 further outlines, with the exception of burnout (BO) and education all the other variables are characterised by high negative skewness whereas all the variables on the side of kurtosis are evidenced to be platykurtic in shape (meaning all the variables used have their respective kurtosis statistics to be less than the threshold). With the affirmation that, none of the kurtosis and skewness meets the conditions of normality for the study variables, we have strong evidence to conclude that all the series of observed variables do not follow the normal distribution.

\subsection{Correlation Analysis}

In order to examine the nature of relationship between burnout, teamwork and perceived organizational support together with the different control variables (demographic characteristics) the Pearson Product moment of correlation (PPMC) was employed. Summary of the correlation matrix between the pairs of variables are elaborated in Table 5. Considering the correlation analysis between the response variable (BO) and each of the explanatory variables, it can be evidenced that all variables with the exception of gender and teamwork are positively correlated with burnout. This therefore gives the indication that perceived organizational support (POS) together with education, marital status and age 
Table 3. Reliability and validity test results.

\begin{tabular}{|c|c|c|c|c|c|c|c|c|}
\hline Domain & Label & Measurement items & $\begin{array}{c}\text { Factor } \\
\text { loadings }\end{array}$ & $\begin{array}{c}\text { Cronbach's } \\
a\end{array}$ & $\begin{array}{c}\text { Cronbach's } \\
\alpha \text { (if item } \\
\text { deleted) }\end{array}$ & AVE & $\begin{array}{l}\text { KMO- } \\
\text { value }\end{array}$ & B-S test \\
\hline \multirow[t]{14}{*}{ Burnout } & & & & 0.865 & & 0.636 & 0.813 & $3813.451^{* * *}$ \\
\hline & EE1 & The hospital work made me tired & 0.810 & & 0.620 & & & \\
\hline & EE3 & I worry that work would affect my mood & 0.714 & & 0.621 & & & \\
\hline & EE4 & I often feel exhausted & 0.824 & & 0.612 & & & \\
\hline & EE5 & At the end of the day, I feel very tired & 0.809 & & 0.622 & & & \\
\hline & PA2 & My patients often complain about me & 0.701 & & 0.652 & & & \\
\hline & PA3 & I can effectively influence others through work & 0.765 & & 0.683 & & & \\
\hline & PA5 & I have the ability to create a relaxed work environment. & 0.773 & & 0.696 & & & \\
\hline & PA7 & I often make small mistakes in my work & 0.772 & & 0.652 & & & \\
\hline & PA8 & I would like to study or work by myself & 0.776 & & 0.688 & & & \\
\hline & PA9 & I worry that patients are not happy with the way I handle problems & 0.805 & & .635 & & & \\
\hline & DP1 & I often blame my patients & 0.790 & & 0.661 & & & \\
\hline & DP4 & I felt nervous and afraid after a medical mistake & 0.778 & & 0.627 & & & \\
\hline & DP5 & I always treat patients with caution & 0.827 & & 0.637 & & & \\
\hline \multicolumn{3}{|c|}{ Teamwork } & & 0.917 & & 0.613 & 0.908 & $5462.095^{* * *}$ \\
\hline & TWV1 & During the task, my team feels full of energy & 0.829 & & 0.903 & & & \\
\hline & TWV2 & Willingness to do extra work without pay & 0.718 & & 0.922 & & & \\
\hline & TWV3 & Encouraging members to promote active participation & 0.790 & & 0.906 & & & \\
\hline & TWD1 & My team is enthusiastic about the task & 0.809 & & 0.905 & & & \\
\hline & TWD2 & Information sharing and problem solving & 0.849 & & 0.902 & & & \\
\hline & TWD3 & Cooperating with superiors to complete work & 0.791 & & 0.906 & & & \\
\hline & TWA1 & When my team is working, we forget everything else around us & 0.772 & & 0.908 & & & \\
\hline & TWA2 & Job changes acceptance & 0.790 & & 0.906 & & & \\
\hline & TWA3 & Maintenance of a good cooperative relationship & 0.780 & & 0.908 & & & \\
\hline \multicolumn{4}{|c|}{ Perceived Organizational support } & 0.915 & & 0.705 & 0.957 & $11,707.440^{* * *}$ \\
\hline & POS1 & The hospital provides me with stable job security & 0.765 & & 0.906 & & & \\
\hline & POS2 & The hospital cares about my personal growth and personal life & 0.815 & & 0.908 & & & \\
\hline & POS3 & $\begin{array}{l}\text { The hospital will pay my salary and bonus according to my } \\
\text { performance }\end{array}$ & 0.819 & & 0.903 & & & \\
\hline & POS4 & The hospital provides me with a good working environment & 0.800 & & 0.905 & & & \\
\hline & POS5 & The treatment the hospital gave me was fair and reasonable & 0.709 & & 0.901 & & & \\
\hline & POS6 & $\begin{array}{l}\text { The hospital was willing to take responsibility for my medical } \\
\text { actions }\end{array}$ & 0.790 & & 0.903 & & & \\
\hline & POS7 & Hospitals should ensure the safety of their doctors (medical personnel) & 0.762 & & 0.907 & & & \\
\hline & POS8 & $\begin{array}{l}\text { Even at the expense of some benefits, the hospital has to stick to } \\
\text { its established philosophy }\end{array}$ & 0.824 & & 0.908 & & & \\
\hline & POS9 & $\begin{array}{l}\text { The hospital encourages doctors (medical staff) to an active part } \\
\text { in its mission building }\end{array}$ & 0.798 & & 0.908 & & & \\
\hline
\end{tabular}


Table 4. Summary of descriptive statistics.

\begin{tabular}{ccccc}
\hline Variables & Mean Statistic & Std. Deviation Statistic & Skewness Statistic & Kurtosis Statistic \\
\hline Gender & 1.610 & 0.489 & -0.437 & -1.813 \\
Education & 5.340 & 0.823 & 0.320 & 0.135 \\
Marital Status & 1.680 & 0.506 & -0.326 & -0.893 \\
Age & 34.670 & 9.597 & 0.598 & -0.483 \\
POS & 4.148 & 0.740 & -0.869 & 0.471 \\
BO & 2.910 & 0.393 & 0.111 & 0.929 \\
TW & 4.287 & 0.675 & -1.138 & 1.317 \\
\hline
\end{tabular}

Table 5. Correlation and multicollinearity tests.

\begin{tabular}{cccccccccc}
\hline Variable & BO & Gender & Education & $\begin{array}{c}\text { Marital } \\
\text { Status }\end{array}$ & Age & TW & POS VIF & Tolerance \\
\hline BO & 1.000 & & & & & & - & - \\
Gender & $-0.085^{* * *}$ & 1.000 & & & & & 1.117 & 0.896 \\
Education & $0.122^{* * *}$ & $-0.282^{* * *}$ & 1.000 & & & & 1.119 & 0.893 \\
Marital Status & $0.046^{*}$ & $-0.085^{* * *}$ & $0.133^{* * *}$ & 1.000 & & & 1.615 & 0.619 \\
Age & 0.030 & $-0.190^{* * *}$ & $0.191^{* * *}$ & $0.613^{* * *}$ & 1.000 & & 1.672 & 0.598 \\
TW & 0.013 & $0.069^{* *}$ & -0.015 & $0.052^{*}$ & -0.011 & 1.000 & 1.527 & 0.655 \\
POS & $0.095^{* *}$ & 0.030 & $0.058^{* *}$ & 0.006 & -0.032 & $0.581^{* * *} 1.000$ & 1.524 & 0.656 \\
\hline
\end{tabular}

Note: ${ }^{*},{ }^{* *},{ }^{* *}$ represents $10 \%, 5 \%$ and $1 \%$ level of significance.

enhances burnout among physicians whereas gender and teamwork (TW) leads to reduced physician burnout. Again, taking into account the correlation matrix between the pairs of explanatory variables of interest (TW and POS), we evidence a substantial positive correlation between the mentioned variables indicating both TW and POS all move in the positive direction meaning a surge in one variable leads to increase the other.In addition, an essential issue is that, the study used numerous (multiple) variables (independent variables) as elaborated from Equation (5) to Equation (7), which is most likely to lead to an unembroidered collinearity. Hence, to address this issue, a correlation matrix between the explanatory variables (control variables included) is conducted (this is highlighted in Table 5 as well). A screening from the cross-correlation matrix gives weak associations for all the possible pairs of independent variables, where the corresponding correlation coefficients are far less than 0.5 . This result of weak correlations amid the pairs of explanatory variables insinuates that, there exist no issues of collinearity (multi-collinearity). This is thus supported by the tolerance and variance inflation factor (VIF) test values from the last two columns of Table 5. Notably, for there to be no issues of multicollinearity in terms of the VIF and Tolerance test, the VIF for each variable is expected to be less than 5 whereas that of the Tolerance is supposed to be higher than 0.2 . 


\subsection{Coefficient Estimation}

Preliminarily, after the confirmation that all variables of interest are sufficient in enough for data reduction, pigeon-holed by good construct validity and reliability with no issues of multicollinearity, it is of interest to estimate the existing relationships amid variables so as to test the various hypotheses developed in the study. Thus, to analyse whether perceived organizational support (POS) efficiently moderates the relationship between teamwork and burnout, which is the main goal of the study, three regression models were constructed in a hierarchical framework based on the step-wise approach to compare the different effects to be estimated. The first model in the hierarchy only estimated the effect of demographic characteristic of respondents (as control variables) on burnout without considering the main variables of interest. These control variables as already mentioned included gender, age, level of education and marital status of respondents. As outlined in Table 6, gender is evidenced to have a significant negative effect on burnout of physicians $(B=-0.046, \mathrm{p}<0.05)$ whereas education contrarily is identified to have a significant positive effect on burnout $(B=$ $0.051, \mathrm{p}<0.05)$. This therefore gives the indication that gender is somehow a factor that is capable having an effect on burnout among physicians being a male or female. This is therefore in line with the studies of Maslach, Schaufeli [35] who in terms of gender specifically reported that males significantly experience high cynicism compared to females. In support, Wang and Wang [47] also found gender from the general perspective to have negative effect on burnout. On the contrary, this finding wasn't supported by the research of Bellamy and Ramsay [48] who made it clear that female gender experience higher levels of burnout due to higher role demands. In the case of education, the positive significant effect suggest that higher level of education leads to increased burnout. This can be attributed to the fact that when one has higher educational background or qualifications he or she is highly expected to be knowledgeable and as well have high level of experience. This as a result makes the demand for their service in various health facilities high thereby increasing their respective workloads which consequently leads to upsurge their burnout level. This finding relating to the positive affiliation between education level of physicians and burnout is not in tandem with the research of Wang and Wang [47]. Further, marital status $(B=0.035, \mathrm{p}>0.05)$ and age $(B=-0.001, \mathrm{p}>0.05)$ though appear to be statistically insignificant had positive and negative corresponding effect on burnout. In the case of marital status though its effect is insignificant, the positive effect evidenced may due to the fact that, health practitioners who are married have responsibilities both at work and home. Therefore, in order to promote work-family balance physician burnout is likely to increase. Also, on the side of unmarried and divorced health workers, there is a likelihood that they might take up extra role or task after their normal work shift or during working hours since they do not have any extra responsibility to handle at home. On the other hand, the positive effect of age on burnout though insignificant may sug- 
gest that majority of the research respondents were evidenced to be in their early prime ages or youthful ages (Ref: Table 1) indicating how energetic and less prone they are to burnout. There is therefore an expectation that young physicians can handle workload and have no or less burnout effect compared to the aged who would experience some form of burnout after engaging in similar work task. Interestingly, the nature of effect of the various demographic characteristics (control variables) are evidenced to be homogeneous across all the estimated model specified in the study.

In the case of the second model as specified in Equation (6), the variable teamwork (TW) and perceived organizational support (POS) are included in addition to the control variables to test the main effects. Notably, TW is witnessed to have a statistically significant adverse effect on burnout, thus the higher the degree of teamwork among physicians the lesser the level of burnout (BO) $(B=$ $-0.042, \mathrm{p}<0.05$ ). Practically, teamwork (TW) having negative affiliation with physician burnout is due to many factors. For instance, this can be attributed to the fact that, physicians share workload which helps to reduce individual workload and also further makes them complete their tasks on time as compared to working individually. This evidenced effect on burnout from teamwork is in line with the works of Westman, Bakker [24]. Additionally, the variable POS on the other hand has positive significant effect of burnout with a parameter estimate of 0.065 and a probability value of 0.000 which is far less than the 0.05 level of significance. This therefore implicates that increase in the level of perceived organizational support, will trigger burnout among physician. This outcome though unexpected may suggest that, when health workers perceive that their work would be given administrative support in line of performing their duties and do not receive such organizational support, they end up not being able to cope with job demands which in the long-run increases their burnout levels. This outcome is therefore in tandem with the findings reported by Walters and Raybould [49] who also reported a negative relationship between perceived organizational behaviour and burnout among physicians.

In the context of the final model as specified in Equation (7), the interaction term of perceived organizational support (POS) and teamwork (TW) denoted as $\mathrm{TW}^{\star}$ POS was included together with the control variables and teamwork (TW) separately. As expected the moderating effect of POS on the relationship between teamwork (TW) and burnout (BO) is identified to be positive and statistically significant $(B=0.066, \mathrm{p}<0.05)$. This in a statistical view point indicates that as POS increases, there is resultant effect on TW which increases while BO reduces. This therefore affirms the hypothesis that the relationship between teamwork and burnout is significantly moderated by perceived organisational support. With regards to the practical implication of this moderating effect, it is clear that a one size fit approach cannot aid in dealing with physician burnout. As suggested by Panagioti, Panagopoulou [9] a bottom up approach is more effective in dealing with physician burnout which involves physicians in the re- 
designing of healthcare service delivery. Therefore, to achieve the best intervention impact and reduce physician burnout, potential strategies must be integrated and a systemic approach should be employed. With regards to the diagnostic test for the various estimated models the R-square together with the adjusted R-squared and F-statistics were utilized (See: Table 6). Results from the mentioned tests unveils though the R-square and adjusted R-squared are not substantial enough, the specified models still proofed to be statistically significant since all the F-test estimates pertaining to the estimated models are significant at $1 \%$ level. Notably, the small R-square values infers that, there is high likely to be no issues of multicollinearity which support the results obtained from the correlation matrix together with the VIF and Tolerance tests amid explanatory variables.

\section{Conclusions}

Even though there has been quite a number of researches that have been performed in the case of the liaison between teamwork and burnout among physicians, this current study using the data from a sample of 938 physicians from various hospitals in the Jiangsu province has analysed the moderating role of perceived organizational support on the relationship between teamwork and physician burnout. To achieve the study objective, we constructed research models, developed hypotheses, obtained data using a well-structured questionnaire and as well performed series of regression analysis in a hierarchical framework. Preliminarily, data pertaining to the variables employed were characterized by a very good construct validity and reliability with no issues of multicollinearity. Base on the estimation of the series of multiple regressions specified in the study

Table 6. Hierarchical Linear regression estimation results: the buffering effect of POS on the relationship between TW and $\mathrm{BO}$.

\begin{tabular}{ccccccccccc}
\hline & \multicolumn{3}{c}{ Model 1 } & \multicolumn{3}{c}{ Model 2 } & \multicolumn{3}{c}{ Model 3 } \\
\cline { 2 - 10 } & $B$ & $S E$ & t-test & $B$ & $S E$ & t-test & $B$ & $S E$ & t-test \\
\hline Constant & $2.696^{* * *}$ & 0.116 & 23.234 & $2.659^{* * *}$ & 0.139 & 19.087 & $2.567^{* * *}$ & 0.138 & 18.628 \\
Gender & $-0.046^{*}$ & 0.027 & -1.669 & $-0.047^{*}$ & 0.028 & -1.696 & $-0.045^{*}$ & 0.027 & -1.652 \\
Education & $0.051^{* * *}$ & 0.016 & 3.095 & $0.050^{* * *}$ & 0.016 & 3.093 & $0.045^{* * *}$ & 0.016 & 2.783 \\
Marital Status & 0.035 & 0.032 & 1.096 & 0.034 & 0.032 & 1.058 & 0.024 & 0.025 & 0.952 \\
Age & -0.001 & 0.002 & -0.685 cont & -0.001 & 0.002 & -0.664 & -0.001 & 0.002 & -0.500 \\
TW & & & & $-0.042^{*}$ & 0.019 & -2.211 & -0.032 & 0.023 & -1.381 \\
POS & & & & $0.065^{* * *}$ & 0.021 & 3.066 & $0.047^{* * *}$ & 0.017 & 2.721 \\
TW*POS & & & & & & & & $0.066^{* *}$ & 0.133 & 2.016 \\
R-Square & 0.019 & & & 0.029 & & & 0.031 & & \\
R-square adj. & 0.015 & & & 0.023 & & & 0.023 & & \\
F Test Value & $4.527^{* * *}$ & & & $3.665^{* * *}$ & & & $4.187^{* * *}$ & & \\
\hline
\end{tabular}


we finally concluded that, in term of demographic characteristics as control variables, gender and education were identified to significantly impact burnout across all specified models. Considering the variables of interest, teamwork significantly was identified as potential factor that aids in reducing burnout among physicians which lead to the affirmation of the study's first hypothesis. Finally, as the main focus of the study, perceived organizational support (POS) was witnessed to play a very vital role in improving teamwork (TW) and reducing burnout among physician. This therefore suggests that perceived organizational behaviour (POS) moderates significantly the affiliations between teamwork and physician burnout thus confirming the second hypothesis of the study. The study results therefore highlight the essence of promoting organisational support in dealing with physician burnout and teamwork simultaneously. Further the study relying on the various outcomes illustrates the value of fostering a positive team environment, collaboration, and cooperation in order to create more vigorous, committed, and absorbed teams, which will increase the success of accomplishing work objectives on time.

The study recommends that in order to address physician burnout, both an individual and a systematic institutional level approach should be used in mitigating burnout. Management should be advised to implement strategies to reassure employees of the company's commitment to them, further redesigning the jobs of health workers by increasing the number of resources available within the system, thereby increasing opportunities for socialization, solving issues related to staff, introducing regular team meetings at which suggestions and criticisms are welcomed, and creating a permanent mechanism to aid future problem solving which needs to be implemented in the various health organizations in the province.

\section{Conflicts of Interest}

The authors declare no conflicts of interest regarding the publication of this paper.

\section{References}

[1] Ang, S.Y., et al. (2016) Demographics and Personality Factors Associated with Burnout among Nurses in a Singapore Tertiary Hospital. BioMed Research International, 2016, Article ID: 6960184. https://doi.org/10.1155/2016/6960184

[2] Leiter, M.P. and Maslach, C. (2009) Nurse Turnover: The Mediating Role of Burnout. Journal of Nursing Management, 17, 331-339. https://doi.org/10.1111/j.1365-2834.2009.01004.x

[3] Humphries, N., et al. (2014) Quality of Care and Health Professional Burnout: Narrative Literature Review. International Journal of Health Care Quality Assurance, 27, 293-307. https://doi.org/10.1108/IJHCQA-08-2012-0087

[4] Shanafelt, T.D., et al. (2016) Longitudinal Study Evaluating the Association between Physician Burnout and Changes in Professional Work Effort. Mayo Clinic Proceedings, 91, 422-431. https://doi.org/10.1016/j.mayocp.2016.02.001 
[5] Shanafelt, T.D., et al. (2010) Burnout and Medical Errors among American Surgeons. Annals of Surgery, 251, 995-1000. https://doi.org/10.1097/SLA.0b013e3181bfdab3

[6] Montgomery, A., et al. (2015) Job Demands, Burnout, and Engagement among Nurses: A Multi-Level Analysis of ORCAB Data Investigating the Moderating Effect of Teamwork. Burnout Research, 2, 71-79. https://doi.org/10.1016/j.burn.2015.06.001

[7] McEwan, D., et al. (2017) The Effectiveness of Teamwork Training on Teamwork Behaviors and Team Performance: A Systematic Review and Meta-Analysis of Controlled Interventions. PLoS ONE, 12, e0169604. https://doi.org/10.1371/journal.pone.0169604

[8] Rousseau, V., Aubé, C. and Savoie, A. (2006) Teamwork Behaviors: A Review and an Integration of Frameworks. Small Group Research, 37, 540-570. https://doi.org/10.1177/1046496406293125

[9] Panagioti, M., et al. (2017) Controlled Interventions to Reduce Burnout in Physicians: A Systematic Review and Meta-Analysis. JAMA Internal Medicine, 177, 195-205. https://doi.org/10.1001/jamainternmed.2016.7674

[10] Olson, K., et al. (2019) Organizational Strategies to Reduce Physician Burnout and Improve Professional Fulfillment. Current Problems in Pediatric and Adolescent Health Care, 49, Article ID: 100664. https://doi.org/10.1016/j.cppeds.2019.100664

[11] Eisenberger, R., et al. (1986) Perceived Organizational Support. Journal of Applied Psychology, 71, 500-507. https://doi.org/10.1037/0021-9010.71.3.500

[12] Baran, B.E., Shanock, L.R. and Miller, L.R. (2012) Advancing Organizational Support Theory into the Twenty-First Century World of Work. Journal of Business Psychology, 27, 123-147. https://doi.org/10.1007/s10869-011-9236-3

[13] Marchand, C. and Vandenberghe, C. (2016) Perceived Organizational Support, Emotional Exhaustion, and Turnover: The Moderating Role of Negative Affectivity. International Journal of Stress Management, 23, 350. https://doi.org/10.1037/str0000020

[14] Rhoades, L. and Eisenberger, R.J. (2002) Perceived Organizational Support: A Review of the Literature. Journal of Applied Psychology, 87, 698-714. https://doi.org/10.1037/0021-9010.87.4.698

[15] Hur, W.-M., et al. (2015) The Moderating Role of Perceived Organizational Support on the Relationship between Emotional Labor and Job-Related Outcomes. Management Decision, 53, 605-624. https://doi.org/10.1108/MD-07-2013-0379

[16] Altinoz, M., et al. (2016) The Influence of Organization Support Perceived in Enterprises on Burnout Feeling: A Field Research. Procedia-Social and Behavioral Sciences, 235, 427-434. https://doi.org/10.1016/j.sbspro.2016.11.053

[17] Bakker, A.B. and Demerouti, E. (2007) The Job Demands-Resources Model: State of the Art. Journal of Managerial Psychology, 22, 309-328.

https://doi.org/10.1108/02683940710733115

[18] Demerouti, E. and Bakker, A.B. (2011) The Job Demands-Resources Model: Challenges for Future Research. SA Journal of Industrial Psychology, 37, 1-9. https://doi.org/10.4102/sajip.v37i2.974

[19] Bakker, A.B., Demerouti, E. and Verbeke, W. (2004) Using the Job Demands-Resources Model to Predict Burnout and Performance. Human Resources Management, 43, 83-104. https://doi.org/10.1002/hrm.20004

[20] Hoonakker, P., Carayon, P. and Korunka, C. (2013) Using the Job-Demands-Resources 
Model to Predict Turnover in the Information Technology Workforce-General Effects and Gender Differences. Horizons of Psychology, 22, 51-65.

https://doi.org/10.20419/2013.22.373

[21] Xanthopoulou, D., et al. (2007) When Do Job Demands Particularly Predict Burnout? Journal of Managerial Psychology, 22, 766-786.

https://doi.org/10.1108/02683940710837714

[22] Lewig, K.A., et al. (2007) Burnout and Connectedness among Australian Volunteers: A Test of the Job Demands-Resources Model. Journal of Vocational Behavior, 71, 429-445. https://doi.org/10.1016/j.jvb.2007.07.003

[23] Hakanen, J.J., Bakker, A.B. and Schaufeli, W.B. (2006) Burnout and Work Engagement among Teachers. Journal of School Psychology, 43, 495-513.

https://doi.org/10.1016/j.jsp.2005.11.001

[24] Westman, M., et al. (2011) Crossover of Job Demands and Emotional Exhaustion within Teams: A Longitudinal Multilevel Study. Anxiety, Stress \& Coping, 24, 561-577. https://doi.org/10.1080/10615806.2011.558191

[25] Busch, C., Deci, N. and Laackmann, M. (2013) Teamwork and Health: The Influence of Team Characteristics on Coping and Health among Low-Qualified Workers. Gio-Gruppe-Interaktion-Organisation-Zeitschrift Fuer Angewandte Organisationspsychologie, 44, 133-151.

[26] González-Morales, M.G., et al. (2012) Perceived Collective Burnout: A Multilevel Explanation of Burnout. Anxiety, Stress Coping, 25, 43-61.

https://doi.org/10.1080/10615806.2010.542808

[27] Welp, A., et al. (2019) Teamwork and Clinician Burnout in Swiss Intensive Care: The Predictive Role of Workload, and Demographic and Unit Characteristics. Swiss Medical Weekly, 149, w20033. https://doi.org/10.4414/smw.2019.20033

[28] Punch, K.F. (2013) Introduction to Social Research: Quantitative and Qualitative Approaches. Sage, London.

[29] Maslach, C., Jackson, S.E. and Leiter, M.P. (1996) MBI: Maslach Burnout Inventory. CPP, Incorporated, Sunnyvale.

[30] Wang, Y., et al. (2019) Burnout in Chinese Social Work: Differential Predictability of the Components of the Maslach Burnout Inventory. International Journal of Social Welfare, 28, 217-228. https://doi.org/10.1111/ijsw.12339

[31] Maslach, C., et al. (1986) Maslach Burnout Inventory. Vol. 21. Consulting Psychologists Press, Palo Alto.

[32] Salanova, M., Llorens, S. and Schaufeli, W.B. (2011) Yes, I Can, I Feel Good, and I Just Do It! On Gain Cycles and Spirals of Efficacy Beliefs, Affect, and Engagement. Applied Psychology, 60, 255-285. https://doi.org/10.1111/j.1464-0597.2010.00435.x

[33] Torrente, P., et al. (2012) From "I" to "We": The Factorial Validity of a Team Work Engagement Scale. In: Neves, J. and Gonçalves, S.P., Eds., Occupational Health Psychology. From Burnout to Well-Being, Edições Sílabo, Lisboa, 333-355.

[34] Schaufeli, W. and Enzmann, D. (1998) The Burnout Companion to Study and Practice: A Critical Analysis. CRC Press, Boca Raton.

[35] Maslach, C., Schaufeli, W.B. and Leiter, M.P. (2001) Job Burnout. Annual Review of Psychology, 52, 397-422. https://doi.org/10.1146/annurev.psych.52.1.397

[36] Bonanno, G.A., et al. (2007) What Predicts Psychological Resilience after Disaster? The Role of Demographics, Resources, and Life Stress. Journal of Consulting Clinical Psychology, 75, 671. https://doi.org/10.1037/0022-006X.75.5.671

[37] Rodríguez, I., et al. (2001) The Demands-Control-Support Model, Locus of Control 
and Job Dissatisfaction: A Longitudinal Study. Work Stress and Health, 15, 97-114. https://doi.org/10.1080/02678370110066968

[38] Hu, X., et al. (2020) Does Innovation Type Influence Firm Performance? A Dilemma of Star-Rated Hotels in Ghana. Sustainability, 12, 9912.

https://doi.org/10.3390/su12239912

[39] Cramer, D. (2003) Advanced Quantitative Data Analysis. McGraw-Hill Education (UK), London.

[40] Helmers, C. and Rogers, M. (2011) Does Patenting Help High-Tech Start-Ups? Research Policy, 40, 1016-1027. https://doi.org/10.1016/j.respol.2011.05.003

[41] Podsakoff, N. (2003) Common Method Biases in Behavioral Research: A Critical Review of the Literature and Recommended Remedies. Journal of Applied Psychology, 88, 879-903. https://doi.org/10.1037/0021-9010.88.5.879

[42] Nunnally, J.C. (1978) Psychometric Theory. 2nd Edition, McGraw Hill, London.

[43] O’Leary-Kelly, S.W. and Vokurka, R.J. (1998) The Empirical Assessment of Construct Validity. Journal of Operations Management, 16, 387-405. https://doi.org/10.1016/S0272-6963(98)00020-5

[44] Özdamar, Ş., Roden, M.F. and Billor, M.Z. (2017) Petrology of the Shoshonitic Çambaşı pluton in NE Turkey and Implications for the Closure of the Neo-Tethys Ocean: Insights from Geochemistry, Geochronology and Sr-Nd Isotopes. Lithos, 284, 477-492. https://doi.org/10.1016/j.lithos.2017.04.025

[45] Hair, J.F., et al. (1998) Multivariate Data Analysis. Vol. 5. Prentice Hall, Upper Saddle River.

[46] Bagozzi, R.P. and Yi, Y. (1988) On the Evaluation of Structural Equation Models. Journal of the Academy of Marketing Science, 16, 74-94. https://doi.org/10.1007/BF02723327

[47] Wang, Q. and Wang, C. (2020) Reducing Turnover Intention: Perceived Organizational Support for Frontline Employees. Frontiers of Business Research in China, 14, 1-16. https://doi.org/10.1186/s11782-020-00074-6

[48] Bellamy, P.A. and Ramsay, K. (1994) Barriers to Women Working in Corporate Management. Australian Government Publishing Service.

[49] Walters, G. and Raybould, M. (2007) Burnout and Perceived Organisational Support among Front-Line Hospitality Employees. Journal of Hospitality Tourism Management, 14, 144-156. https://doi.org/10.1375/jhtm.14.2.144 